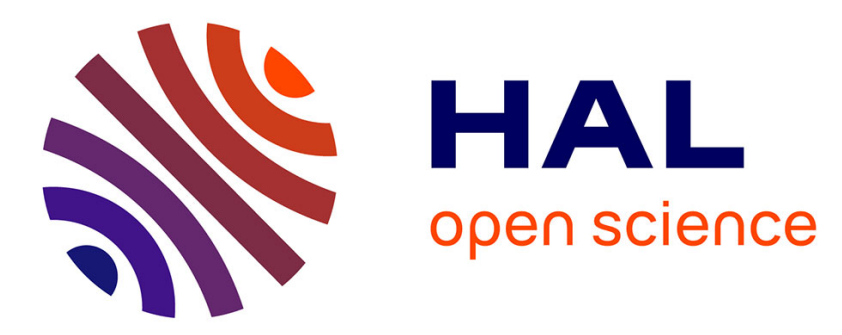

\title{
Influence of training background on the relationships between plantarflexor intrinsic stiffness and overall musculoskeletal stiffness during hopping
}

\author{
Giuseppe Rabita, Antoine Couturier, Daniel Lambertz
}

\section{To cite this version:}

Giuseppe Rabita, Antoine Couturier, Daniel Lambertz. Influence of training background on the relationships between plantarflexor intrinsic stiffness and overall musculoskeletal stiffness during hopping. European Journal of Applied Physiology, 2008, 103, pp.163-171. 10.1007/s00421-008-0679-9 . hal01561386

\section{HAL Id: hal-01561386 \\ https://hal-insep.archives-ouvertes.fr/hal-01561386}

Submitted on 18 Jul 2017

HAL is a multi-disciplinary open access archive for the deposit and dissemination of scientific research documents, whether they are published or not. The documents may come from teaching and research institutions in France or abroad, or from public or private research centers.
L'archive ouverte pluridisciplinaire HAL, est destinée au dépôt et à la diffusion de documents scientifiques de niveau recherche, publiés ou non, émanant des établissements d'enseignement et de recherche français ou étrangers, des laboratoires publics ou privés. 


\title{
Influence of training background on the relationships between plantarflexor intrinsic stiffness and overall musculoskeletal stiffness during hopping
}

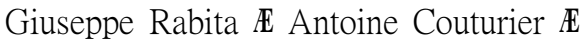 \\ Daniel Lambertz
}

Abstract The aim of this study was to characterize the influence of intrinsic musculotendinous and musculoarticular stiffness of plantarflexor muscles on (1) the overall musculoskeletal stiffness and (2) the performance during stretch-shortening cycles-type exercise. The influence of plyometric training background on these relationships was also analyzed. Musculotendinous $\left(\mathrm{SI}_{\mathrm{MT}}\right)$, passive $\left(K_{P}\right)$ and active $\left(\mathrm{SI}_{\mathrm{MA}}\right)$ musculoarticular stiffnesses were quantified, using quick-release and sinusoidal perturbation tests, on nine French elite long or triple jumpers (athlete group, AG) and nine control subjects (CG). These ergometric parameters were related with the lower-limb stiffness $\left(K_{\text {leg }}\right)$ and the maximal performance $\left(H_{\max }\right)$ measured from a force platform during vertical hopping. AG showed a significantly higher $\mathrm{SI}_{\mathrm{MT}}\left(2.76 \mathrm{rad}^{-1}\right), K_{P}\left(55.6 \mathrm{~N} \mathrm{~m} \mathrm{rad}{ }^{-1}\right), K_{\text {leg }}$ $\left(30.3 \mathrm{kN} \mathrm{m}^{-1}\right)$ and $H_{\max }(0.48 \mathrm{~m})$ compared to CG (1.83 $\mathrm{rad}^{-1}, 37.8 \mathrm{~N} \mathrm{~m} \mathrm{rad}^{-1}, 19.6 \mathrm{kN} \mathrm{m}^{-1}$ and $0.38 \mathrm{~m}$, respectively). $K_{\text {leg }}$ was not significantly correlated with any of the intrinsic stiffness parameters $\left(\mathrm{SI}_{\mathrm{MT}}, \mathrm{SI}_{\mathrm{MA}}\right.$ or $\left.K_{P}\right)$. For $\mathrm{AG}$, a strong and negative correlation was observed between $H_{\max }$ and $K_{\text {leg }}$. These data indicate that, while elite jumpers presented higher stiffness of both musculotendinous and passive musculoarticular structures, a high compliance of musculoskeletal system was beneficial to optimize the performance in vertical hopping for these athletes. We suggested that neuromuscular strategies were

\section{G. Rabita (\&) - A. Couturier}

Laboratoire de Biomécanique et de Physiologie, INSEP, 11, Avenue du Tremblay, 75012 Paris, France

e-mail: giuseppe.rabita@insep.fr

\section{Lambertz}

UMR CNRS 6600, Biomécanique et Génie Biomédical, Université de Technologie de Compiègne, Compiègne, France designed to counterbalance this higher intrinsic stiffness to solve the problem of the conflicting requirement of the musculotendinous elements: increase in compliance to enhance the elastic recoil and increase in stiffness for a better force transmission to the periphery.

Keywords Series elastic component · Triceps surae · Spring-mass model $\cdot$ Elite jumpers $\cdot$ Hopping in place

\section{Introduction}

It is well documented that the storage and the subsequent release of elastic energy in stretch-shortening cycles (SSC) improve muscle efficiency (Cavagna 1977). The muscle force and power potentiation during SSC depends, among other factors [for review, see Komi (2000)], on the behavior of the series elastic component (SEC) during and immediately after the stretching phase. The stiffness of the SEC is more or less implied according to the hierarchical level of a given anatomical structure. For example, according to the modified Hill muscle model (Shorten 1987), the tendon elasticity represents only the passive part of the SEC stiffness. In humans, to characterize both parts of the SEC stiffness [i.e., the active (muscle fibers) and the passive (tendon) ones], musculotendinous (MT) stiffness was usually measured by adapting classical methods (i.e., quick-release or controlled-released) developed for isolated muscle (Pousson et al. 1990; Hof 1998). Moreover, in active conditions, a global musculoarticular (MA) stiffness was also measured in humans, usually using sinusoidal perturbations (SPs; Lambertz et al. 2001; McLachlan et al. 2006). This last stiffness reflects not only the elastic properties of the SEC stiffness but also the effects of passive elastic structures including skin, ligaments and 
articular surfaces. These different intrinsic stiffnesses (tendon, MT, MA) were measured in a pseudo-isolated context, under controlled and initial constant conditions.

The stiffness of the whole body could be evaluated in a more global manner. During hopping in place or running, human legs normally behave like compression springs so that the overall musculoskeletal (MS) system can be described as a simple spring-mass model (Blickhan 1989; McMahon and Cheng 1990). The stiffness of this MS system is determined from the ratio of the peak ground reaction force to the center of mass displacement. Specific joint stiffness (JS) could also be calculated (ratio of the change in joint moment to joint angular displacement) during running or jumping tasks. It could be noticed that, in contrast to the evaluation conditions of intrinsic stiffnesses, the musculoskeletal (MS) or joint (JS) stiffnesses are evaluated in a functional context and then could be modulated via the neuromuscular control.

Recently, some studies aimed to characterize the relationships between intrinsic and musculoskeletal (or joint) stiffness during hopping. Kubo et al. (2007) failed to observe significant relationships between the Achilles tendon stiffness and the ankle joint stiffness during jumping tasks using single joint. Previously, McLachlan et al. (2006) did not report significant influence of the intrinsic ankle MA stiffness on the musculoskeletal stiffness during vertical hopping. This last result questioned the real influence of intrinsic stiffness on the global one. Indeed, it was previously shown that in vertical hopping conditions, it was shown that the adjustment of the ankle stiffness is the primary mechanism for the adjustment of the overall musculoskeletal stiffness, which is relatively insensitive to changes in knee or hip stiffness (Farley and Morgenroth 1999).

Relatively few studies aimed to characterize these relationships. However, a better understanding of the influence of intrinsic stiffness on the global stiffness during SSC-type exercises could also highlight the link between elastic properties of the anatomical structures described above and the performance in SSC-type exercise. These aspects are still open to discussion. Among the numerous studies on this purpose, beyond dissimilarities, opposing influences were reported; high (Burgess et al. 2007; Bojsen-Moller et al. 2005; Farley and Morgenroth 1999), optimal (Arampatzis et al. 2001; Voigt et al. 1995; Anderson and Pandy 1993) or low (Kubo et al. 1999; Walshe and Wilson 1997; Bobbert 2001) stiffness being beneficial to the performance.

To better specify the kind of the relationships between intrinsic and global musculoskeletal stiffnesses, analyses of high-level athletes using high intensity plyometric exercises seem interesting. Firstly, it is well known that training status influences both intrinsic (Kubo et al. 2000a, b) and
MS stiffnesses. For example, the stiffness of vastus lateralis tendon was shown to be increased in long distance runners (Kubo et al. 2000a). Furthermore, when leg stiffness, measured in jumping conditions, was compared between high-level athletes of different sports, different profiles were determined according to the sports categories (Laffaye et al. 2005). Secondly, several studies have also demonstrated that plyometric training leads to changes in intrinsic stiffness. For example, Burgess et al. (2007) have recently shown that such training induced an increase in medial gastrocnemius tendon stiffness specifically measured by ultrasonography. Previously, Pousson et al. (1995) observed after 5-week plyometric training an increased stiffness of the MT complex in the triceps surae, associated with increased performance in jumping involving SSC (counter movement jump and drop jump). In the same way, Spurrs et al. (2003) obtained an increase in MA stiffness measured after 6 weeks of plyometric training by using damped oscillations.

The aim of this study was to characterize, for two groups with different plyometric training background, the relationships between ankle intrinsic (MT and MA) stiffness and (1) the overall musculoskeletal stiffness and (2) the performance during SSC-type exercise. For this purpose, data obtained from international long and triple jumpers and from a control group (CG) were compared.

\section{Methods}

\section{Subjects}

Nine sedentary subjects [age $27.5 \pm 5.2$ (SD) years; mass $66.1 \pm 4.9 \mathrm{~kg}$; height $175.3 \pm 3.0 \mathrm{~cm}$ ] composed the CG and nine high level long or triple jumpers [age $24.5 \pm 3.9$; mass $72.9 \pm 4.9 \mathrm{~kg}$; height $181.7 \pm 5.1 \mathrm{~cm}$ ] constituted the athlete group (AG). The AG was composed of five long jumpers and four triple jumpers belonging to the French elite. Their mean maximal performances were $7.84 \pm 0.52 \mathrm{~m}$ and $16.75 \pm 0.58 \mathrm{~m}$, respectively. The subjects participated in the study after giving their informed consent in accordance with the recommendations of the local ethical committee.

\section{Material}

\section{Ergometric tests}

The ankle ergometer used for this study has been described in detail elsewere (Tognella et al. 1997). Briefly, it consisted of two main units: (1) a power unit that contained the actuator, its power supply unit, position 
and torque transducers, and its associated electronics, and (2) a driving unit composed of a PC-type computer equipped with a specific 12-bit A/D converter and a timer board. Angular displacement was measured with an optical digital sensor, and angular velocity was captured from a resolver bound to the rotor. A tachometer was used for the measure of the velocities greater than $15.7 \mathrm{rad} \mathrm{s}^{-1}$. Torque was obtained using a strain-gauge torque transducer. Specific menu-driven software controlled all procedures and recorded the mechanical variables (1,000 $\mathrm{Hz}$ sampling frequency) for later analysis. An oscilloscope gave the subject visual feedback on the procedure in progress.

\section{Hopping test}

During the hopping test, the vertical component of the ground reaction force was collected from a force platform (Kistler, type 9281A11) signal (1,000 Hz sampling frequency) via an acquisition card (type ATMIO16, National Instrument) driven by a commercialized software (Daqware, National Instrument). Data processing was made off line with Origin 6.1 (OriginLab Corporation, Northampton, USA).

\section{Experimental protocol}

\section{Ergometric tests}

Ergometric tests were carried out while the subject laid on an adjustable table with the knee and the ankle joints bent to $90^{\circ}$. Trunk and thigh were restrained by straps. The subject was positioned so that the actuator rotation axis was placed at the level of the mean bi-malleolar axis. In the first test, the maximal voluntary contraction (MVC) was determined in plantar flexion under isometric conditions. Three trials were carried out and the best performance was considered as the true MVC of the day. Then, quick release (QR) and sinusoidal perturbation (SP) tests were imposed in a random order. QR consisted of a sudden release of the actuator while the subject performed an isometric plantar flexion at the neutral ankle position. Three measurements were then collected at each submaximal isometric torques (25, 50 and $75 \%$ MVC). SP consisted of a $3^{\circ}$ peak-to-peak harmonic angular displacement imposed around the neutral position of the ankle joint. During these perturbations, the subject maintained a mean constant torque equal to one of the following: $0 \%$ (passive test), 25, 50 or $75 \%$ MVC. Each $\mathrm{SP}$ was performed during $4 \mathrm{~s}$ at frequencies ranging from 4 to $16 \mathrm{~Hz}$ and imposed randomly.

\section{Hopping test}

Subjects performed two-legged vertical hopping. They were asked to hop as high as possible while minimizing the ground contact time. After a familiarization with the procedure, two trials of four jumps were required after a little period (3-5 s) of stability on the platform. For control purposes, the subjects were instructed to keep their hands on their hips during the jumps.

For each subject, the order of the tests was selected randomly. The total duration of the session lasted approximately $60 \mathrm{~min}$.

\section{Data processing}

\section{Musculotendinous stiffness}

For each QR trial, the analyzed parameters were as follows: (1) isometric torque just before the release $\left(T_{\text {iso }}\right)$; (2) changes in angular position (Dh) and changes in angular acceleration [ $\mathrm{Dh}^{00}$, obtained as first derivative of the angular velocity signal $\left.\left(\mathrm{h}^{0}\right)\right]$. These two parameters were characterized within the first $20 \mathrm{~ms}$ at the beginning of the QR movement; (3) inertia (I) calculated by considering the transition between the static phase and the dynamic phase: at this point, acceleration is maximal $\left(\mathrm{h}^{00}{ }_{\max }\right)$ and static torque equals dynamic torque $\left(T_{\text {iso }}=I^{00}{ }_{\max }\right)$. As reported in previous studies (Goubel and Pertuzon 1973), the angular MT stiffness $\left(S_{\mathrm{MT}}\right)$ was measured at the start of the movement, i.e., when the so-called SEC in Hill muscle model (Hill 1938) is supposed to recoil, according to the formula

$S_{\mathrm{MT}} 1 / 4 \mathrm{IDh}=\mathrm{Dh}$

$S_{\mathrm{MT}}$ was related to the corresponding isometric torque $\left(T_{\text {iso }}\right)$ initially exerted by the subject. The slope of the linear stiffness-torque relationship so obtained was defined as a stiffness index of the MT stiffness $\left(\mathrm{SI}_{\mathrm{MT}}\right)$.

\section{Musculoarticular stiffness}

SP tests were used to construct a Bode diagram from (1) the ratio between the amplitude of averaged $h$ and the amplitude-modulated torque $\left(T_{\bmod }\right)$ changes (i.e., gain curve) and (2) the phase shift between $\mathrm{h}$ and $T_{\text {mod }}$ (phase curve), both parameters being plotted against the imposed frequencies. In this processing, the torque signal was analyzed at the driving frequency to neglect the nonlinearities of the response (Kearney and Hunter 1990). Such a Bode diagram reflects the classical features of a mixed mechanical contribution from elasticity $(K)$, viscosity $(B)$ 
and inertia $(I)$ of the MA system (Kearney and Hunter 1990). Using identification techniques (Levy 1959), a second-order model including such parameters was adjusted to the Bode diagram as expressed by the formula:

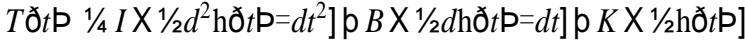

where $T$ is the external torque $(\mathrm{N} \mathrm{m})$ and $\mathrm{h}$ is the angular position (rad).

So, for each level of torque, the MA stiffness $K_{\mathrm{MA}}(\mathrm{N}$ $\mathrm{m} \mathrm{rad}^{-1}$ ) was determined. $K_{\mathrm{MA}}$ values were related to the maintained torque $(T)$. The slope of the linear $K_{\mathrm{MA}}-T$ relationship so obtained was defined as a stiffness index of the MA stiffness $\left(\mathrm{SI}_{\mathrm{MA}}\right)$. In addition, MA stiffness mea-

sured in passive condition, i.e., $0 \% \mathrm{MVC}$, was analyzed independently and noted as $K_{P}$.

\section{Stiffness of the overall musculoskeletal system during hopping}

Figure 1 shows a typical force platform recording for one subject. A spring-mass model was used to calculate the stiffness of the leg spring $\left(K_{\mathrm{leg}}\right)$ during the ground contact phase of hopping in place (Blickhan 1989; McMahon and Cheng 1990). $K_{\text {leg }}$, combined stiffness of the two legs, was calculated from the ratio of the peak ground reaction force $\left(F_{\text {peak }}\right)$ to the maximal displacement of the leg spring $(\mathrm{D} L)$. $K_{\operatorname{leg}} 1 / 4 F_{\text {peak }}=\mathrm{D} L$

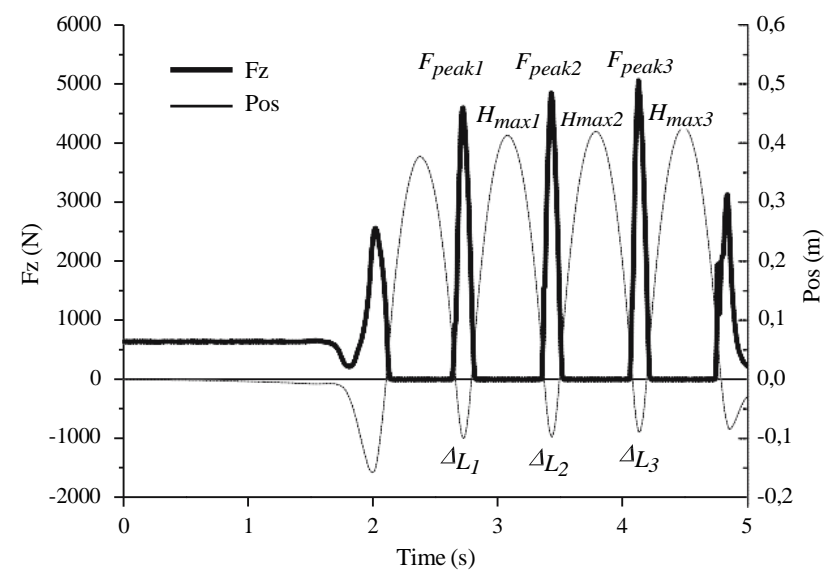

Fig. 1 Typical recording of vertical component of the ground reaction force $(\mathrm{Fz}$, in $\mathrm{N})$ and changes in vertical displacement of the center of mass during the hopping test (Pos, in $\mathrm{m}$ ). The overall musculoskeletal stiffness was calculated from the ratio between the peak ground reaction force $\left(F_{\text {peak }}\right)$ and the maximal displacement of the leg spring $(\mathrm{D} L)$ obtained during the first-to-third ground contact phases. The maximal positive vertical displacement of the center of mass ( $H_{\max }$, hopping height) was calculated from the averaged values obtained during the second-to-fourth jumps
$\mathrm{D} L$ was set as the negative vertical displacement of the center of mass (COM) during the ground contact phase and was calculated by twice integrating the vertical acceleration with respect to time. $F_{\text {peak }}$ and $\mathrm{D} L$ values obtained during the first-to-third ground contact phase were analyzed (see Fig. 1). Such model was applied considering that in our imposed conditions the body behaved like a simple spring-mass system as attested by the force-displacement relationships (Fig. 2).

The performance during hopping was attested by the maximal positive vertical displacement (i.e., the maximal jump height, $\left.H_{\max }\right)$. As reported above, the vertical displacement of the COM was calculated by twice integrating the vertical acceleration with respect to time (Fig. 1). For each parameter, the values of both trials were averaged.

\section{Correction to body size}

Based on dimensional theory, the parameters were expressed here with respect to body mass using the allometric parameters listed in Table 1 (Jaric 2003; BojsenMoller et al. 2005). Allometric parameters were used to express the data relatively to body mass according to the following equation

$P_{n} 1 / 4 P=\mathrm{BM}^{a p}$

where $P$ is the analyzed parameter, $\mathrm{BM}$ is body mass and ap is the allometric parameter.

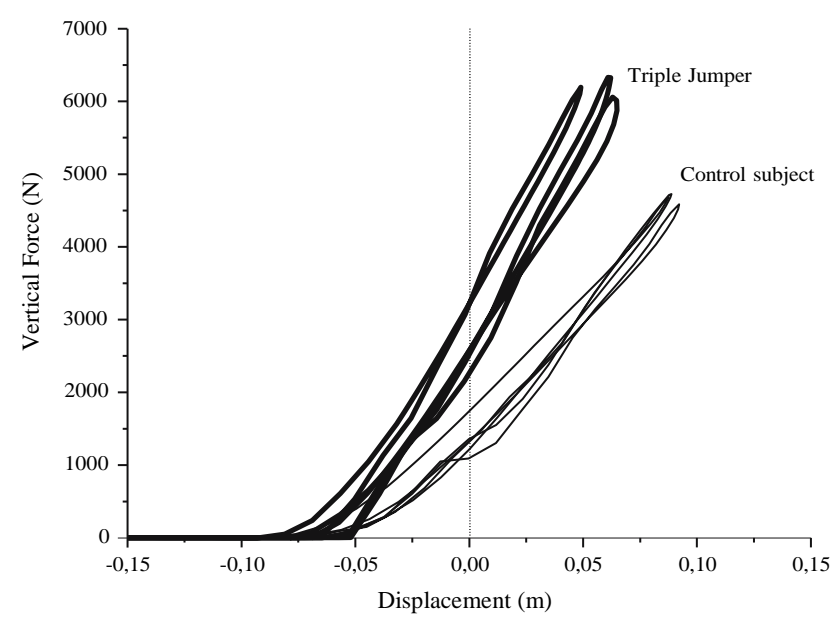

Fig. 2 Force-displacement relationships recorded during the first-tothird ground contact phases for a control subject (thin line) and a triple jumper (thick line) representative of their respective group. The displacement (in meters) corresponds to the variation of the center of mass position ( 0 is equal to the vertical COM position when the subject is stood upright before the test) 
Table 1 Correction to body size

\begin{tabular}{ll}
\hline Variable & Allometric parameter \\
\hline Ankle-ergometer parameters & \\
MVC $(\mathrm{N} \mathrm{m})$ & 1 \\
Intrinsic stiffness $\left(\mathrm{N} \mathrm{m} \mathrm{rad}{ }^{-1}\right)$ & $1 / 3$ \\
Hopping parameters & \\
Hopping height $(\mathrm{m})$ & 0 \\
Hopping stiffness $\left(\mathrm{kN} \mathrm{m}^{-1}\right)$ & $1 / 3$
\end{tabular}

Allometric parameters were used to express the data relatively to body mass; the following equation was used to obtain the normalized parameter: $P_{n}=P / \mathrm{BM}^{\mathrm{ap}}$, where $P$ is the respective parameter, $\mathrm{BM}$ is body mass and ap is the allometric parameter

\section{Statistical analysis}

The comparison between long and triple jumpers was analyzed using the nonparametric Mann-Whitney's test. The Student $t$ test was used to compare high-level jumpers and sedentary subjects. Correlations between the different parameters were investigated using the Pearson product moment correlation. All statistical analyses were conducted at $P \backslash 0.05$. Values were represented as mean $( \pm \mathrm{SD})$.

\section{Results}

Comparison between long and triple jumpers

The mean $( \pm \mathrm{SD})$ values of intrinsic elastic properties analyzed in the present study are presented in Table 2 for each high-level athlete subgroup. The nonparametric analyses did not show any significant difference between long and triple jumpers $(P \boldsymbol{[} \quad 0.05)$. Thus, the data of long and triple jumpers were analyzed together and compared with those of the CG as described below.

Comparison between athletes and controls

Raw and normalized intrinsic and hopping parameters are presented in Table 3.
Ergometric tests

As expected, mean normalized MVC values during isometric plantar flexion were significantly higher $(P \backslash 0.05)$ for AG than for CG. For the plantarflexor MT stiffness index, the mean coefficients of determination $R^{2}$ of the linear $K_{\mathrm{MT}} T_{\text {iso }}$ relationships were $0.86( \pm 0.08)$ for $\mathrm{AG}$ and $0.85( \pm 0.09)$ for CG. One of the main notable results is that normalized stiffness index values were more than $50 \%$ higher $(P \backslash 0.01)$ for the AG compared to the $\mathrm{CG}$ (Table 3).

Considering the plantarflexor MA system, the mean coefficients of determination $R^{2}$ of linear $K_{\mathrm{MA}}-T$ relationships were $0.95( \pm 0.02)$ for AG and $0.91( \pm 0.06)$ for CG. The mean $\mathrm{SI}_{\mathrm{MA}}$ values normalized to the body size did not differ significantly $(P[0.05)$ between both groups. However, the athletes presented significantly higher $(P \backslash 0.01)$ passive MA stiffness values $\left(K_{P}\right)$ compared to CG (Table 3).

\section{Hopping tests}

Each parameter obtained during the hopping test revealed significant differences between the elite jumpers and the controls. Raw and normalized hopping parameters are presented in Table 3. The maximal height $\left(H_{\max }\right)$ measured during hopping was $26 \%$ higher $(P \backslash 0.01)$ for AG compared to CG (Table 3$). K_{\operatorname{leg}}$ was $51.8 \%$ higher $(P \backslash 0,05)$ for the athletes than for the control subjects.

Correlations with the hopping stiffness

For each group, the correlations between the stiffness of the overall musculoskeletal system during hopping $\left(K_{\text {leg }}\right)$ and the other parameters were established. Results are presented in Fig. 3. Whatever be the tested group, normalized $K_{\text {leg }}$ was not significantly correlated with any intrinsic stiffness parameter obtained from ergometric testing $\left(\mathrm{SI}_{\mathrm{MT}}\right.$, $\mathrm{SI}_{\mathrm{MA}}$ or $K_{P}$ ). For the jumpers, it could be noticed that a strong and negative correlation was observed between the

Table 2 Comparison of intrinsic parameters between long and triple jumpers

\begin{tabular}{|c|c|c|c|c|c|c|c|c|}
\hline & \multicolumn{4}{|l|}{ Raw values } & \multicolumn{4}{|c|}{ Normalized to body mass } \\
\hline & Long jumpers & Triple jumpers & Difference $\%$ & $P$ & Long jumpers & Triple jumpers & Difference $\%$ & $P$ \\
\hline MVC & $102.7 \pm 16.2$ & $102.4 \pm 16.6$ & -0.25 & ns & $1.44 \pm 0.28$ & $1.42 \pm 0.34$ & 1.63 & $\mathrm{~ns}$ \\
\hline $\mathrm{SI}_{\mathrm{MT}}$ & $2.64 \pm 0.89$ & $2.97 \pm 0.76$ & 12.7 & $\mathrm{~ns}$ & $55.5 \pm 18.4$ & $61.8 \pm 15.6$ & -11.4 & $\mathrm{~ns}$ \\
\hline $\mathrm{SI}_{\mathrm{MA}}$ & $4.59 \pm 0.65$ & $4.11 \pm 0.7$ & -10.6 & $\mathrm{~ns}$ & $79.8 \pm 13.2$ & $72.3 \pm 15.4$ & 9.4 & $\mathrm{~ns}$ \\
\hline$K_{P}$ & $55.3 \pm 8.4$ & $56.0 \pm 8.0$ & 1.19 & ns & $13.3 \pm 1.9$ & $13.4 \pm 2.4$ & -0.98 & $\mathrm{~ns}$ \\
\hline
\end{tabular}


Table 3 Comparison in intrinsic and hopping parameters between jumpers and controls

\begin{tabular}{|c|c|c|c|c|c|c|c|c|}
\hline & \multicolumn{3}{|l|}{ Raw values } & \multirow[b]{2}{*}{$P$} & \multicolumn{4}{|c|}{ Normalized to body mass } \\
\hline & AG & $\mathrm{CG}$ & Difference $\%$ & & AG & CG & Difference $\%$ & $P$ \\
\hline \multicolumn{9}{|c|}{ Intrinsic } \\
\hline MVC & $102.5 \pm 15.3$ & $87.1 \pm 15.6$ & 17.7 & 0.034 & $1.43 \pm 0.29$ & $1.31 \pm 0.21$ & 8.9 & 0.049 \\
\hline $\mathrm{SI}_{\mathrm{MT}}$ & $2.76 \pm 0.80$ & $1.82 \pm 0.46$ & 52.1 & 0.0085 & $57.8 \pm 16.5$ & $38.1 \pm 6.1$ & 51.7 & 0.007 \\
\hline $\mathrm{SI}_{\mathrm{MA}}$ & $4.38 \pm 0.68$ & $4.23 \pm 0.83$ & 3.5 & ns & $76.4 \pm 13.8$ & $69.1 \pm 12.3$ & 10.6 & ns \\
\hline$K_{P}$ & $55.6 \pm 7.7$ & $37.8 \pm 10.5$ & 47.1 & 0.013 & $13.3 \pm 1.9$ & $9.3 \pm 2.7$ & 42.7 & 0.003 \\
\hline \multicolumn{9}{|c|}{ Hopping } \\
\hline$K_{\text {leg }}$ & $30.3 \pm 10.5$ & $19.6 \pm 7.80$ & 54.6 & 0.029 & $7.29 \pm 2.50$ & $4.86 \pm 1.97$ & 51.8 & 0.041 \\
\hline$H_{\max }$ & $0.48 \pm 0.06$ & $0.38 \pm 0.04$ & 27.9 & $\backslash 0.001$ & $0.48 \pm 0.06$ & $0.38 \pm 0.04$ & 26.0 & $\backslash 0.001$ \\
\hline
\end{tabular}
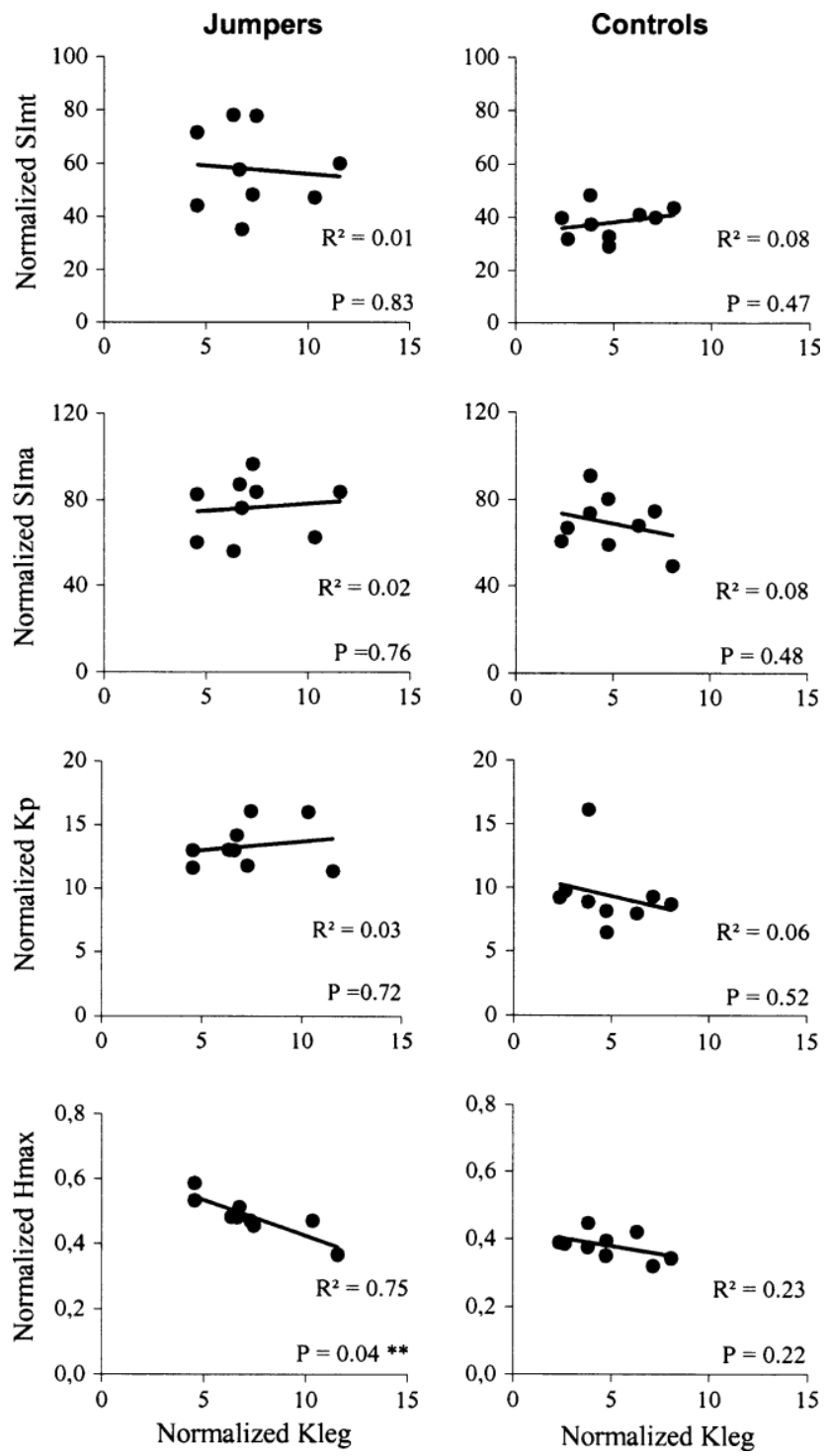

Fig. 3 Relationships between normalized musculoskeletal stiffness and normalized intrinsic stiffness $\left(\mathrm{SI}_{\mathrm{MT}}, \mathrm{SI}_{\mathrm{MA}}\right.$ and $\left.K_{P}\right)$ or jumping performance $\left(H_{\max }\right)$ for jumpers and controls maximal height reached during hopping and $K_{\text {leg. }}$ This relationship was not significant for the $\mathrm{CG}$.

\section{Discussion}

One of the main results of the present study is that elite long and triple jumpers presented higher MT stiffness of the plantarflexors as well as higher passive ankle MA stiffness compared to sedentary subjects. Whatever be the tested group, the intrinsic elastic properties of the ankle (MT and MA) were not significantly related with the global musculoskeletal stiffness. It is also noteworthy that the vertical hopping performance was inversely correlated with the musculoskeletal stiffness only for the jumpers.

\section{Intrinsic parameters}

Considering the maximal force production in isometric conditions, the CG values corresponded to the data reported in close ankle and knee joint angle conditions. For example, Arampatzis et al. (2006) measured ankle moment of about $85 \pm 5 \mathrm{~N} \mathrm{~m}$ during maximal plantar flexion contractions with the ankle and knee joint angle, respectively, at $90^{\circ}$ and $110^{\circ}$. As expected, the jumpers developed a higher maximal isometric torque than the sedentary subjects. This difference could be explained by morphological muscle adaptations to short-sprint training program, especially a shift toward type II fibers and/or an increase in both type I and type II fiber area (Ross and Leveritt 2001).

For the MT stiffness, elite jumpers presented higher $\mathrm{SI}_{\mathrm{MT}}$ values of about $50 \%$ compared to the sedentary subjects. The mean $\mathrm{SI}_{\mathrm{MT}}$ values obtained in control subjects $\left(1.83 \pm 0.49 \mathrm{rad}^{-1}\right)$ were in agreement with those found in previous studies using similar methodologies. For example, the recent study of Ochala et al. (2004) reported $\mathrm{SI}_{\mathrm{MT}}$ values of $2.03 \pm 0.37 \mathrm{rad}^{-1}$ for sedentary subjects. 
This result corroborates previous investigations, which analyzed the modifications of the plantarflexors MT stiffness in humans after a short period (5 or 6 weeks) of plyometric training (Pousson et al. 1995; Spurrs et al. 2003). Such type of exercise, which consisted of various jumps and hops in both horizontal and vertical plane, is largely involved in the training of long and triple jumpers. Such modifications in the MT stiffness seem then to be logical adaptations to the demand of jump exercises. In the present experiment, MT stiffness was assessed by means of the quick-release technique. As in isolated muscle, a major portion of the MT stiffness resides in the tendon (passive fraction), whereas muscle fibers constitute the active fraction (Huxley and Simmons 1971). Previous studies have shown that fast twitch fibers were more compliant than slow twitch fibers (Goubel and Marini 1987). Moreover, several studies have shown that the shift toward fast twitch fibers in rat soleus muscle resulting from jumping training was associated to a decrease in SEC stiffness (Pousson et al. 1991; Almeida-Silveira 1994). Given these points, it is reasonable to assume that the main MT adaptations in the elite jumpers were localized in the passive fraction (tendons) of the MT complex. These assumptions were in line with the recent study of Burgess et al. (2007) who showed, using ultrasonography, that 6 weeks of plyometric training induced an increase in medial gastrocnemius tendon stiffness.

With regard to the MA stiffness obtained in passive $\left(K_{P}\right)$ or active $\left(\mathrm{SI}_{\mathrm{MA}}\right)$ conditions from the SP, the results were in good agreement with the values reported by previous studies (Hunter and Kearney 1982; Lambertz et al. 2001; Toft et al. 1991). For example, in the study of Lambertz et al. (2001), $K_{P}$ and $\mathrm{SI}_{\mathrm{MA}}$ values were, respectively, $39.1 \pm 3.9 \mathrm{~N} \mathrm{~m} \mathrm{rad}^{-1}$ and $4.74 \pm 0.61 \mathrm{rad}^{-1}$.

For the passive MA stiffness $\left(K_{P}\right)$, the AG presented significant higher values than those obtained in the CG. $K_{P}$ reflects the effects of passive muscle, tendon and articular structures (including ligaments, skin and articular surfaces). In other studies, differences in passive MA stiffness due to changes in the functional demand (hyper- vs hyposolicitation) were attributed to adaptations similar to those found in collagenic structures (Cornu et al. 1997; Lambertz et al. 2001). Given these findings, it can be hypothesized that the higher passive stiffness values found in the elite jumpers are due to differences in collagenic structures (e.g., tendon, ligaments). Functionally, an increased passive MA stiffness coming from ligamentous structures seems an interesting solution to the problem related to the stability of the ankle during the long or the triple jumps. Indeed, while in long jumping high impacts occur with forces up to 10 bodyweight (Seyfarth et al. 1999), in the second jump step phase of the triple jump, the ground reaction forces in the braking phase are greater than 15 bodyweight (Perttunen et al. 2000). Such ligamentous adaptations in the elite jumpers could prevent ankle instability, and thus, decrease the risk of injury. Nevertheless, further analyses are required to confirm these hypotheses and to determine precisely the contribution of each implied passive structure to the higher stiffness in jumpers.

For the global MA stiffness $\left(\mathrm{SI}_{\mathrm{MA}}\right)$, the athletes did not show significant difference from the controls. The interpretation of this result is delicate considering that this parameter is assumed to reflect changes in both active MT and passive MA stiffness (Cornu et al. 1997; Lambertz et al. 2001; Ochala et al. 2004). Indeed, in previous studies, it was found that $\mathrm{SI}_{\mathrm{MT}}$ and $K_{P}$ were altered by the same amount but in the opposite direction (Lambertz et al. 2001). The authors put forth the hypothesis that the changes in passive ankle joint structures resulted from an adaptative response that allows the global musculo-articular system to remain unchanged. This hypothesis was comforted by recent investigations showing that changes in both parameters were negatively correlated in long distance runners (unpublished results). However, in the present study, both $\mathrm{SI}_{\mathrm{MT}}$ and $K_{P}$ were higher in the elite jumpers. So the comparable $\mathrm{SI}_{\mathrm{MA}}$ values between jumpers and controls must be interpreted differently than an opposite adaptations in active and passive structures. Cornu et al. (1997) have previously shown that 7 weeks of plyometric training leads to a significant decrease of $\mathrm{SI}_{\mathrm{MA}}$. The given interpretation was a fiber type transition phenomenon (toward type II fibers) which leads to an increase in compliance of the active MA system. Furthermore, the increase in stiffness of the muscle and joint system with increasing torque results from the activation of muscle fibers [for review, see Kearney and Hunter (1990)]. From this point of view, it can be hypothesized that the unchanged $\mathrm{SI}_{\mathrm{MA}}$ of the present study might be due to different elastic properties of passive and active structures, i.e., tendinous structures versus muscle, between elite jumpers and control subjects.

\section{Intrinsic versus hopping parameters}

The stiffness values of the overall musculoskeletal system corresponded to the data reported in similar conditions (Farley et al. 1991). It was not the aim of the article to describe the musculoskeletal behavior with respect to the hopping frequency. Nevertheless, it could be noticed that even at frequencies lower than $2.2 \mathrm{~Hz}$, considered to be the frequency under which the body could not behave in a spring like manner (Farley et al. 1991), the measures have shown linear force-displacement relationships (Fig. 2), attesting for a spring-mass behavior.

In elite jumpers, the musculoskeletal stiffness and the maximal height during the hopping was increased 
approximately in the same amount than changes in plantarflexor MT stiffness. However, neither $K_{\operatorname{leg}}$ nor $H_{\max }$ was significantly correlated with intrinsic parameters. The fact that $\mathrm{SI}_{\mathrm{MA}}$ was not correlated with the $K_{\text {leg }}$ was expected (McLachlan et al. 2006). But we also failed to observe a significant correlation between MT stiffness and MS stiffness or the performance. As reported recently, during running or jumping tasks, an appropriate musculoskeletal stiffness could be provided by high and well-coordinated activation patterns of the leg extensors muscles during the preactivation and the eccentric phase (Kyröläinen et al. 2003). It was previously shown that these aspects of the neuromuscular control could explain the differences between athletes (triple jumpers) and nonathletes during drop jump (Viitasalo et al. 1998). Although no electromyography was realized in the present study, with regard to these previous studies (Viitasalo et al. 1998; Kyröläinen et al. 2003), the more appropriate musculoskeletal stiffness during hopping performances in jumpers may be mainly explained in terms of neuromuscular functioning. The adaptations of intrinsic mechanical properties seem to contribute only weakly to the higher overall musculoskeletal stiffness. These results corroborated the recent finding of Kubo et al. (2007).

The essential role of the neuromuscular functioning is also revealed by the relationships between $K_{\text {leg }}$ and $H_{\text {max }}$. Interestingly, while no correlation was observed in the $\mathrm{CG}$ between these parameters, when we focus on the AG, a strong and negative correlation was found. In other words, the lower the musculoskeletal stiffness the greater the hopping height. These results corroborate the study of Seyfarth et al. (1999), which show that there is a low minimal musculoskeletal stiffness for optimum long jump performance. They are also in agreement with number of studies reporting that a long compliant SEC in plantarflexors maximizes performance in squat (Bobbert 2001; Hof et al. 2002), countermovement and drop jumping (Walshe and Wilson 1997).

The paradoxical observations between the mechanical adaptations of intrinsic MT properties (higher stiffness in the jumpers) and the influence of the musculoskeletal stiffness on the performance highlight the complexity of the relationships between the elastic properties at the different anatomical levels. While speculative, it may be suggested that the neuromuscular control was organized to counterbalance the increased MT stiffness. It is established that the muscle tendon complex has to satisfy two contradictory requirements: an increase in compliance to increase the elastic recoil and an increase in stiffness for a better force transmission to the periphery (Cavagna et al. 1981). As a result of plyometric training, it was proposed that the opposite adaptations between the passive (tendon) and the active (muscle fibers) parts of the MT complex could solve these conflicting requirements (Cornu et al. 1997). The results of the present study, together with the data reported previously (Bojsen-Moller et al. 2005; Pousson et al. 1995), seem to indicate that, for athletes who show an adaptation of intrinsic elastic properties, the neuromuscular control allows to maintain a certain amount of musculoskeletal compliance during SSC-type exercise. Both aspects of the storage-release process could then efficiently participate in the higher performance. Further analyses are required to confirm these assumptions.

\section{Conclusion}

The present data demonstrated that elite long and triple jumpers presented higher stiffness of both MT and passive MA structures. These adaptations of elastic properties seem to contribute only weakly to the higher overall musculoskeletal stiffness observed in athlete subjects during vertical hopping tasks. For these highly trained subjects, it appears that a high musculoskeletal compliance was beneficial to optimize the performance in these SSC-type exercises. We suggested that the neuromuscular strategies in elite jumpers were designed to counterbalance this higher intrinsic stiffness. From a functional point of view, the balance between high intrinsic MT stiffness and low musculoskeletal stiffness could allow to solve the problem of the conflicting requirement of the MT complex: to increase compliance to enhance the elastic recoil and to increase stiffness for a better transmission of force to the periphery.

Acknowledgments This study was part of a major work supported by the French Minister of Health, Sports and Associative Life. We thank Professor Francis Goubel and Professor Chantal Pérot for their implication in the collaboration between the Technological University of Compiègne (UTC) and the French National Institute of Sports (INSEP).

\section{References}

Almeida-Silveira MI, Perot C, Pousson M, Goubel F (1994) Effects of stretch-shortening cycle training on mechanical properties and fibre type transition in the rat soleus muscle. Pflugers Arch 427:289-294

Anderson FC, Pandy MG (1993) Storage and utilization of elastic strain energy during jumping. J Biomech 26:1413-1427

Arampatzis A, Schade F, Walsh M, Brüggemann G (2001) Influence of leg stiffness and its effect on myodynamic jumping performance. J Electromyogr Kinesiol 11:355-364

Arampatzis A, Karamanidis K, Stafilidis S, Morey-Klapsing G, Demonte G, Bruggemann GP (2006) Effect of different ankleand knee-joint positions on gastrocnemius medialis fascicle length and EMG activity during isometric plantar flexion. J Biomech 39:1891-1902 
Bobbert MF (2001) Dependence of human squat jump performance on the series elastic compliance of the triceps surae: a simulation study. J Exp Biol 204:533-542

Bojsen-Moller J, Magnusson SP, Rasmussen LR, Kjaer M, Aagaard P (2005) Muscle performance during maximal isometric and dynamic contractions is influenced by the stiffness of the tendinous structures. J Appl Physiol 99:986-994

Blickhan R (1989) The spring mass model for running and hopping. J Biomech 22:1217-1227

Burgess KE, Connick MJ, Graham-Smith P, Pearson SJ (2007) Plyometric vs. isometric training influences on tendon properties and muscle output. J Strength Cond Res 21:986-989

Cavagna GA (1977) Storage and utilization of elastic energy in skeletal muscle. Exerc Sport Sci Rev 5:89-129

Cavagna GA, Citterio G, Jacini P (1981) Effects of speed and extend of stretching on the elastic properties of active frog muscle. J Exp Biol 91:131-143

Cornu C, Almeida Silveira MI, Goubel F (1997) Influence of plyometric training on the mechanical impedance of the human ankle joint. Eur J Appl Physiol 76:282-288

Farley CT, Morgenroth DC (1999) Leg stiffness primarily depends on ankle stiffness during human hopping. J Biomech 32:267-273

Farley CT, Blickhan R, Saito J, Taylor CR (1991) Hopping frequency in humans: a test of how springs set stride frequency in bouncing gaits. J Appl Physiol 71:2127-2132

Goubel F, Marini JF (1987) Fibre type transition and stiffness modification of soleus muscle of trained rats. Pflugers Arch 410:321-325

Goubel F, Pertuzon E (1973) Evaluation of the elasticity of muscle in situ by the quick-release method. Arch Int Physiol Biochim 81:697-707

Hill AV (1938) The heat of shortening and the dynamic constant of muscle. Proc R Soc Lond B Biol Sci 126:136-195

Hof AL (1998) In vivo measurement of the series elasticity release curve of human triceps surae muscle. J Biomech 31:793-800

Hof AL, Van Zandwijk JP, Bobbert MF (2002) Mechanics of human triceps surae muscle in walking, running and jumping. Acta Physiol Scand 174:17-30

Hunter IW, Kearney RE (1982) Dynamics of human ankle stiffness: variation with mean ankle torque. J Biomech 15:747-752

Huxley AF, Simmons RM (1971) Mechanical properties of the crossbridges of frog striated muscle. J Physiol 218:59-60

Jaric S (2003) Role of body size in the relation between muscle strength and movement performance. Exerc Sport Sci Rev 31:8-12

Kearney RE, Hunter IW (1990) System identification of human joint dynamics. Crit Rev Biomed Eng 18:55-87

Komi PV (2000) Stretch-shortening cycle: a powerful model to study normal and fatigued muscle. J Biomech 33:1197-1206

Kubo K, Kawakami Y, Fukunaga T (1999) Influence of elastic properties of tendon structures on jump performance in humans. J Appl Physiol 87:2090-2096

Kubo K, Kanehisa H, Kawakami Y, Fukunaga T (2000a) Elastic properties of muscle-tendon complex in long-distance runners. Eur J Appl Physiol 81:181-187

Kubo K, Kanehisa H, Kawakami Y, Fukunaga T (2000b) Elasticity of tendon structures of the lower limbs in sprinters. Acta Physiol Scand 168:327-335

Kubo K, Morimoto M, Komuro T, Tsunoda N, Kanehisa H, Fukunaga $T$ (2007) Influences of tendon stiffness, joint stiffness, and electromyographic activity on jump performances unsing single joint. Eur J Appl Physiol 99:235-243

Kyrö läinen H, Finni T, Avela J, Komi PV (2003) Neuromuscular behavior of the triceps surae muscle-tendon complex during running and jumping. Int J Sports Med 24:153-155

Laffaye G, Bardy BG, Durey A (2005) Leg stiffness and expertise in men jumping. Med Sci Sports Exerc 37:536-543

Lambertz D, Perot C, Kaspranski R, Goubel F (2001) Effects of longterm spaceflight on mechanical properties of muscles in humans. J Appl Physiol 90:179-188

Levy EC (1959) Complex curve fitting. IEEE Trans Automat Contr 4:34-43

McLachlan KA, Murphy AJ, Watsford ML, Rees S (2006) The interday reliability of leg and ankle musculotendinous stiffness measures. J Appl Biomech 22:296-304

McMahon TA, Cheng GC (1990) The mechanics of running: how does stifness couple with speed? J Biomech 23(Suppl 1):6578

Ochala J, Lambertz D, Pousson M, Goubel F, Van Hoecke J (2004) Changes in mechanical properties of human plantar flexor muscles in ageing. Exp Gerontol 39:349-358

Perttunen JO, Kyröläinen H, Komi PV, Heinonen A (2000) Biomechanical loading in the triple jump. J Sports Sci 18:363-370

Pousson M, Van Hoecke J, Goubel F (1990) Changes in elastic characteristics of human muscle induced by eccentric exercise. J Biomech 23:343-348

Pousson M, Perot C, Goubel F (1991) Stiffness changes and fibre type transitions in rat soleus muscle produced by jumping training. Pflugers Arch 419:127-130

Pousson M, Legrand J, Bergaud S, Van Hoecke J (1995) Détente et élasticité : effets d'un entraînement pliométrique. Sci Motricité 25:19-26

Ross A, Leveritt M (2001) Long-term metabolic and skeletal muscle adaptations to short-sprint training: implications for sprint training and tapering. Rev Sports Med 31:1063-1082

Seyfarth A, Friedrichs A, Want V, Blickan R (1999) Dynamics of the long jump. J Biomech 32:1259-1267

Shorten MR (1987) Muscle elasticity and human performance. Med Sport Sci 25:1-18

Spurrs RW, Murphy AJ, Watsford ML (2003) The effect of plyometric training on distance running performance. Eur J Appl Physiol 89:1-7

Toft E, Sinkjaer T, Larsen K, Andreassen S (1991) Mechanical and electromyographical responses to stretch of human ankle extensors. J Neurophysiol 65:1402-1410

Tognella F, Mainar A, Vanhoutte C, Goubel F (1997) A mechanical device for studying mechanical properties of human muscles in vivo. J Biomech 30:1077-1080

Voigt M, Simonsen EB, Dyhre-Poulsen P, Klausen K (1995) Mechanical and muscular factors influencing the performance in maximal vertical jumping after different prestretch loads. J Biomech 28:293-307

Viitasalo JT, Salo A, Lahtinen J (1998) Neuromuscular functioning of athletes and non-athletes in the drop jump. Eur J Appl Physiol 78:432-440

Walshe AD, Wilson GJ (1997) The influence of musculotendinous stiffness on drop jump performance. Can J Appl Physiol 22:117-132 